\title{
Childhood trauma and dissociation among women with genito-pelvic pain/penetration disorder
}

This article was published in the following Dove Press journal:

Neuropsychiatric Disease and Treatment

\section{Beliz Özen \\ Y Özay Özdemir \\ E Emrem Beștepe}

Erenköy Mental Health and

Neurological Diseases Education and Research Hospital, Istanbul, Turkey
Correspondence: Y Özay Özdemir Erenköy Mental Health and Neurological Diseases Education and Research Hospital, 34736 Istanbul, Turkey Email ozayozdemirmd@gmail.com
Objective: Causes such as childhood trauma, negative attitude about sexuality, inadequate sexual knowledge and education, relationship problems, and unconscious motivation are reported about psychosexual development in the etiology of genito-pelvic pain/penetration disorder (GPP/PD). There are few studies that focus directly on research etiology of GPP/PD and use structured scales. The aim of this study was to research childhood trauma and dissociation forms among women with GPP/PD.

Patients and methods: Fifty-five women with GPP/PD according to the fifth edition of the Diagnostic and Statistical Manual of Mental Disorders and 61 healthy women with no complaints of sexual function as a control group, in the age range of 18-60 years, were included in this study. Sociodemographic data form, Childhood Trauma Questionnaire (CTQ-28), Dissociative Experiences Scale (DES), and Somatoform Dissociation Questionnaire (SDQ-20) were administered to all participants.

Results: Sexual abuse, emotional abuse, and emotional neglect scores, which comprise the subgroups of CTQ, were found high among women with GPP/PD compared with the control group ( $p=0.003, p=0.006, p=0.001$ ). While a significant difference between the two groups' SDQ scores was obtained ( $p=0.000)$, no significant difference was detected between the two groups' DES scores ( $p=0.392)$.

Discussion: The results evoke the question are genitopelvic pain conditions, vaginismus and dyspareunia, that cannot be explained with a medical cause and that cause penetration disorder, a kind of dissociative symptom prone to develop in some women with childhood psychogenic trauma.

Keywords: dyspareunia, sexual phobia, abuse, sexual dysfunction, intercourse, avoidance

\section{Introduction}

The most frequent sexual dysfunction among women who apply to sexual treatment clinics in our country is observed to be "penetration disorder (PD)," namely vaginismus. ${ }^{1,2}$ There is still much discussion on the naming and classification of vaginismus. The Diagnostic and Statistical Manual of Mental Disorders (DSM) and the International Classification of Diseases systems have been criticized for insufficiently paying attention to etiological assessment and focusing only on phenomenology. It was indicated that cases of vaginismus and dyspareunia showed clinical continuity and were difficult to be differentiated. ${ }^{3,4}$ On the other hand, discussions on whether the fundamental characteristic of vaginismus is pain and/or spasm, fear, or avoidance have continued for years. ${ }^{5}$ Furthermore, until now, there have been several researchers who have approached patients with similar clinical appearance and etiological features with concepts such as "chronic pelvic pain (CPP)" and "vulvar vestibulitis syndrome (VVS). ${ }^{\prime 6-10}$ As a result of all these scientific assessments and discussions, among the changes in the associated section of the fifth edition of DSM (DSM-V) - which is 
the latest version of DSM - dyspareunia and vaginismus diagnoses have been removed, and instead, "genito-pelvic pain (GPP)/PD" diagnoses have been inserted. ${ }^{11}$

In the etiology of vaginismus, reasons such as childhood trauma - sexual, physical, and emotional ${ }^{4,12-14}$ - negative attitudes about sexuality, ${ }^{15}$ inadequate sexual knowledge and education, ${ }^{1,16}$ relational difficulties, ${ }^{17}$ and unconscious motivation based on psychosexual development ${ }^{18,19}$ have been reported.

There are a small number of studies that focus on exploring the etiology of GPP/PD directly and that use structured scales. ${ }^{4,8-10}$ In the related literature, the studies report contradicting results about childhood trauma in GPP/PD patients. While some indicate the presence of trauma - sexual, physical, and emotional ${ }^{4,12-14,20}$ - and insecure attachment possibly due to trauma ${ }^{18}$ in many of the patients, others report no observation of difference from the normal population with regard to a history of trauma. ${ }^{21,22}$ The contradictory results from studies are attributed to differences in methods used in the research. ${ }^{4}$

The period of life when one is most vulnerable to such traumatic events is childhood, when one's ability to cope with trauma is much less developed. ${ }^{23}$ Several authors who support the concept, proposed by Nijenhuis, ${ }^{24}$ that trauma is the foundation of the pathological process for both dissociation and somatoform disorders, have identified dissociative symptoms and a history of trauma as highly prevalent in patients with somatoform disorders. ${ }^{25-27}$ Psychogenic sexual dysfunction among women has been considered an expression of somatoform dissociation, similar to certain somatoform and conversion disorders. ${ }^{8-10,28}$

There are a limited number of studies that investigate dissociation among female patients with GPP/PD. ${ }^{8-10,28}$ Studies often focus on patients identified with GPP or CPP. This study aimed at investigating the prevalence of childhood trauma and forms of dissociation in the patient population with GPP/PD compared with women without GPP/PD.

\section{Patients and methods Sample}

Fifty-five patients who were admitted to Erenköy Mental Health and Neurological Diseases Education and Research Hospital and diagnosed with GPP/PD, in accordance with the DSM-V criteria, were approached and informed about the aims and methods of this study. Among the patients, those who were not illiterate and provided informed consent were enrolled in this study. Other exclusion criteria were defined as intellectual disability, dementia, and psychosis. Sixty-one healthy control subjects with no complaints of sexual function were chosen from hospital staff and their relatives according to the exclusion criteria. The controls were interviewed with the nonpatient version of the Structured Clinical Interview (SCID-NP) for the revised third edition of the DSM to exclude any axis I disorder. ${ }^{29}$ All control subjects were heterosexual and have been sexually active for the previous 6 months. The patients were interviewed with the Structured Clinical Interview for DSM-IV axis I disorders (SCID I). ${ }^{30}$ Forty-nine of the 55 participants in the patient group had a diagnosis of vaginismus, and six had a diagnosis of dyspareunia according to the DSM-IV. A sociodemographic data form was then completed for all the participants. Other data used in this study were obtained by using the Childhood Trauma Questionnaire (CTQ-28), Dissociative Experiences Scale (DES), and Somatoform Dissociation Questionnaire (SDQ-20).

\section{Materials}

\section{Sociodemographic data form}

Developed by the current investigators, the form included questions about the participants' age, marital status, marriage method, duration of marriage/relationship, number of and desire for children, educational background, occupation, place of residence, manner in which the application was made and the motivation behind it, additional history of psychiatric and/or physical illnesses, and the age of first attempt at sexual intercourse. The form was completed by a trained member of the research team.

\section{SCID I}

SCID I is a semi-structured interview developed by First et al. ${ }^{30}$ This widely used interview serves as a diagnostic instrument for DSM-IV axis I psychiatric disorders. Its reliability and validity study in Turkish was carried out by Öztürkçügil et al. ${ }^{31}$

\section{SCID-NP}

The Structured Clinical Interview for DSM-III-R, SCID-NP, is a semi-structured interview developed by Spitzer et al. ${ }^{29}$ It is used to exclude any axis I disorder. Its reliability and validity study in Turkish was carried out by Sorias et al. ${ }^{32}$

\section{CTQ-28}

Bernstein et al initially developed the CTQ with 70 items. ${ }^{33}$ Later, Bernstein et al derived a shorter version with 28 items. ${ }^{34}$ The questionnaire is useful for assessing experiences 
of abuse and neglect before the age of 20 years, retrospectively and quantitatively. It includes subscales for emotional abuse, physical abuse, sexual abuse, emotional neglect, and physical neglect, from which a final total score can be computed. Turkish reliability and validity studies on the questionnaire have been published by Sar et al. ${ }^{35}$

\section{DES}

This scale, developed by Bernstein and Putnam, is utilized to assess the presence of dissociative experiences and the intensity of these experiences. ${ }^{36}$ It includes 28 items with each item scored between 0 and 100, in intervals of 10 , by the subject. An average score is achieved by adding the scores for all items and dividing this sum by 28. In studies conducted in Turkey, among psychiatric patients with an average total score of $\geq 30$, the probability of finding a dissociative disorder, defined as psychoform dissociation, is high. The scale was adapted to Turkish by Yargiç et al. ${ }^{37}$

\section{SDQ-20}

This instrument is used to assess the presence and intensity of dissociative experiences and disorders. It includes a total of 20 items, with each item scored between 1 and 5 by the patient himself or herself, yielding a final total summation score between 5 and 100. The results of studies conducted in Turkey indicate that, among those individuals with an average total score of $\geq 40$, the probability of identifying a dissociative disorder is high; in fact, in several studies, individuals with a score $\geq 35$ were considered to have somatoform dissociation. The reliability and validity studies of the Turkish version of the SDQ have been published by Şar et al. ${ }^{38}$

\section{Procedure}

The participants were evaluated by using the aforementioned scales after the procedure; the aims of this study were explained in detail, and written informed consent was obtained. The study was approved by the institutional review board in Erenköy Mental Health and Neurological Diseases Education and Research Hospital.

\section{Data analysis}

All data were evaluated by using the Statistical Package for Social Sciences software package Version 17.0 (SPSS Inc., Chicago, IL, USA) for Windows. In addition to summarizing data descriptively - as means, standard deviations (SDs), frequencies, and percentiles - inferential analysis was conducted by using the Student's $t$-tests for continuous variables and Pearson $\chi^{2}$ analysis for categorical variables. Differences were identified by using an a priori two-tailed threshold for significance of $p<0.05$ and the calculation of $95 \%$ confidence intervals.

\section{Results}

The average age was 27.8 years for patients and 31.5 years for controls. Table 1 summarizes the sociodemographic characteristics of the study sample. The level of education and age at the first sexual intercourse were compared between the two groups, and no significant differences were identified ( $p=0.303$ and $p=0.415$, respectively).

Subgroup and total CTQ scores are compared between the patients and controls (Table 2). No significant intergroup differences were identified for either physical abuse or physical neglect subdimension. Conversely, significant differences were detected for the emotional abuse $(p=0.006)$, emotional neglect $(p=0.001)$, and sexual abuse $(p=0.003)$ subscores. In each instance, the average score among patients was higher than that among controls. The CTQ total score was also higher among patients than among controls $(p=0.001)$. Patient SDQ scores were significantly higher than those of controls $(p<0.001)$; however, the DES scores of the two groups did not differ (Table 3 ).

Four (7.3\%) individuals in the patient group versus none in the control group were found to have the cutoff score of $\geq 40$, consistent with "somatoform dissociation," a difference that was statistically significant $(p=0.048)$. Conversely, seven patients (12.7\%) and six controls (9.8\%) equaled or exceeded the cutoff score of 30 for "psychoform dissociation" (Table 4).

\section{Discussion}

In our study, according to CTQ evaluation, the scores on sexual and emotional abuse as well as emotional neglect

Table I Sociodemographic characteristics

\begin{tabular}{llll}
\hline & $\begin{array}{l}\text { Patient } \\
(\mathbf{n}=\mathbf{5 5})\end{array}$ & & $\begin{array}{l}\text { Control } \\
(\mathbf{n}=\mathbf{6} \mathbf{I})\end{array}$ \\
\cline { 2 - 2 } & Mean $\pm \mathbf{S D}$ & & Mean $\pm \mathbf{S D}$ \\
\hline Age at assessment (years) & $27.8 \pm 5.6$ & $31.5 \pm 5.4$ \\
Duration of relationship (months) & $45.5 \pm 56.13$ & $89.6 \pm 71.7$ \\
Duration of education (years) & $11.25 \pm 3.3$ & $12.3 \pm 3.8$ \\
Age of first attempt at sexual & $24.01 \pm 3.9$ & $23.3 \pm 3.9$ \\
intercourse (years) & & \\
\hline & $\mathbf{n ~ ( \% )}$ & $\mathbf{n ~ ( \% )}$ \\
\hline Married & $5 I(92.7)$ & $46(75.4)$ \\
Children (I or more) & $5(9.1)$ & $28(46.7)$ \\
\hline
\end{tabular}


Table 2 CTQ results

\begin{tabular}{lllll}
\hline & \multicolumn{1}{l}{ Patient } & & Control & \multirow{2}{*}{ P-value } \\
\cline { 2 - 2 } \cline { 5 - 5 } & Mean \pm SD & & Mean \pm SD & \\
\hline Emotional abuse & $7.8 \pm 3.01$ & & $6.3 \pm 2.3$ & $0.006^{*}$ \\
Physical abuse & $6.1 \pm 2.2$ & & $5.5 \pm 1.6$ & 0.091 \\
Physical neglect & $6.9 \pm 2.1$ & & $6.6 \pm 2.5$ & 0.626 \\
Emotional neglect & $12.03 \pm 5.1$ & & $9.3 \pm 3.4$ & $0.00 I^{*}$ \\
Sexual abuse & $6.7 \pm 3.6$ & & $5.3 \pm 1.1$ & $0.003^{*}$ \\
CTQ total & $39.6 \pm 11.2$ & & $33.3 \pm 8.5$ & $0.00 I^{*}$ \\
\hline
\end{tabular}

Note: *Significance level $p<0.05$.

Abbreviation: CTQ, Childhood Trauma Questionnaire.

were higher in the GPP/PD group than in the control group. These results are consistent with previous studies that report a history of trauma in the majority of vaginismus patients. ${ }^{4,12-14,20}$ However, in the related literature, there are studies that demonstrate no history of trauma in vaginismus cases. $^{21,22}$ It is argued that the contradictory results may be due to methodological differences in studies. ${ }^{4}$ There are a small number of studies that focus on exploring the etiology of PD directly and that use structured scales. ${ }^{4,8-10}$ In one of the oldest records in literature, Malleson describes that among the women with vaginismus most of them had traumatic experiences due to childhood medical treatment, and these made some women prone to the development of vaginismus symptoms. ${ }^{12}$ A study comparing the structured questionnaire results of three groups of women, ie, those with vaginismus, with dyspareunia/VVS, and without penetration difficulties, reported more frequent history of childhood sexual abuse and less positive attitude toward their own gender in the group of women with vaginismus. ${ }^{4}$

Various studies demonstrate the presence of childhood trauma and dissociative symptoms in different somatoform and conversion disorders. ${ }^{39-42}$ Taycan et al observed significantly higher rates of childhood trauma among patients with somatoform disorders and reported that these results indicate association between traumatic stress and somatic complaints among patients with somatoform disorders. ${ }^{41}$ In another study that used CTQ that was used in our study, the prevalence of sexual dysfunction and childhood trauma were observed

Table 3 SDQ and DES results

\begin{tabular}{lllll}
\hline & Patient & & Control & p-value \\
\cline { 2 - 2 } & Mean \pm SD & & Mean \pm SD & \\
\hline SDQ & $27.01 \pm 6.8$ & & $23.4 \pm 3.4$ & $0.000 *$ \\
DES & $13.5 \pm 12.8$ & & $11.4 \pm 11.2$ & 0.392 \\
\hline
\end{tabular}

Note: *Significance level $p<0.05$.

Abbreviations: DES, Dissociative Experiences Scale; SDQ, Somatoform Dissociation Questionnaire.
Table 4 Comparison of DES and SDQ cutoff scores

\begin{tabular}{|c|c|c|c|}
\hline & $\frac{\text { Patient }}{\mathrm{n}(\%)}$ & $\frac{\text { Control }}{\mathrm{n}(\%)}$ & $p$-value \\
\hline \multicolumn{4}{|l|}{ DES } \\
\hline$\geq 30$ & 7 (12.7) & $6(9.8)$ & 0.622 \\
\hline$<30$ & $48(87.3)$ & $55(90.2)$ & \\
\hline \multicolumn{4}{|l|}{ SDQ } \\
\hline$\geq 40$ & $4(7.3)$ & & \\
\hline$<40$ & 51 (92.7) & $61(100)$ & $0.048^{*}$ \\
\hline
\end{tabular}

Note: *Significance level $p<0.05$.

Abbreviations: DES, Dissociative Experiences Scale; SDQ, Somatoform Dissociation Questionnaire.

to be significantly higher among women with fibromyalgia compared with healthy controls, and a relationship between childhood psychic trauma and sexual problems as well as the intensity of the disorder was reported..$^{39}$ Many common features are observed between fibromyalgia and GPP/PD that are disorders both associated with pain: fibromyalgia is more frequent in women, ${ }^{43,44}$ sexual dysfunction is present in most cases, ${ }^{45-47}$ the incidence of childhood trauma ${ }^{48,49}$ and many psychiatric features including dissociative symptoms $\mathrm{s}^{50-52}$ are higher with general population. The findings of our study also support this conclusion.

Another result of our study is that there was no significant difference between the two groups' DES scores (mean $=13.5$, $\mathrm{SD}=12.8$, vs mean $=11.4, \mathrm{SD}=11.2$ ) used to measure "psychoform dissociation," a type of dissociation, which is known to be associated with trauma; however, there was a significant difference between the two groups' SDQ scores ( mean $=27.01, \mathrm{SD}=6.8$, vs mean $=23.4, \mathrm{SD}=3.4$ ), which is used to measure "somatoform dissociation." There are a limited number of studies that investigate dissociation among patients with sexual dysfunction, and in these studies, a history of psychogenic trauma and forms of dissociation are explored among women with CPP without an organic cause known to be particularly associated with dyspareunia and vaginismus. ${ }^{8-10,53}$ Walker et al have observed higher dissociation scores and increased somatic stress among women with CPP and have reported that these women were sexually abused in their childhoods. ${ }^{8}$ Badura et al have also reported the observation of high rates of dissociation as well as somatization in cases with accompanying psychogenic trauma in a patient sample of CPP. ${ }^{9}$ Nijenhuis et al have demonstrated in their study a relationship between somatoform and psychoform dissociation in women with CPP and a history of psychogenic trauma. ${ }^{10}$ Therewith, they reported that the DES scores of CPP patient samples (mean $=8.6, \mathrm{SD}=11.98$ ) were lower than those of the general adult population, despite 
not being in the control group, and the SDQ-20 scores (mean $=25.7, \mathrm{SD}=9.31$ ) were slightly higher than those of patients with the mixed psychiatric disorders. ${ }^{10}$ According to the researchers, in some cases, CPP may relate to trauma, particularly sexual and physical abuse, and may represent a positive somatoform dissociative symptom. ${ }^{10}$ In another study from Italy, it was found that the rate of somatoform dissociation in a sample of 15 including patients with orgasm disorder, vaginismus, and dyspareunia was five times higher compared with a healthy group, and there was an observed strong relationship between psychogenic sexual dysfunction and somatoform dissociation. ${ }^{29}$ In addition, researchers have argued that some psychogenic sexual dysfunctions can be considered as trauma-based disorders and that some of its forms can appear as somatoform dissociative disorders. ${ }^{28}$

The results from previous studies ${ }^{8-10,28,53}$ and our study evoke the question "are 'GPP' conditions - vaginismus and dyspareunia - that cannot be explained with a medical cause and that cause $\mathrm{PD}$, a kind of dissociative symptom, prone to develop in some women with childhood psychogenic trauma?"

In the diagnosis and treatment of patients with GPP/PD, exploring comorbid psychiatric conditions is as important as eliminating organic causes. One of these conditions is childhood psychogenic trauma. Especially if cases that are positive with history are examined in terms of somatoform dissociation, perhaps additional attempts in the treatment of treatment-resistant patients may increase treatment response rates. Along with our results, supporting the idea that at least one group of GPP/PD can be considered as a trauma-based disorder, it can be said that a wider sample study is needed on this subject.

\section{Disclosure}

The authors report no conflicts of interest in this work.

\section{References}

1. Özdemir Ö, Şimşek F, Özkardeş S, İncesu C \& Karakoç B. The unconsummated marriage: its frequency and clinical characteristics in a sexual dysfunction clinic. J Sex Marital Ther. 2008;34(3):268-279.

2. Kayir A. Vaginismus. Türkiye Klinikleri. J Psychiatry-Special Topics. 2009;2(4):48-52.

3. Kaneko K. Penetration disorder: dyspareunia exists on the extension of vaginismus. $J$ Sex Marital Ther. 2001;27(2):153-155.

4. Reissing ED, Binik YM, Khalif S, Cohen D, Amsel R. Etiological correlates of vaginismus: sexual and physical abuse, sexual knowledge, sexual self-schema, and relationship adjustment. J Sex Marital Ther. 2003; 29(1):47-59.

5. Reissing ED, Binik YM, Khalifé S. Does vaginismus exist?: a critical review of the literature. J Nerv Ment Dis. 1999;187(5):261-274.

6. Wijma B, Jansson M, Nilsson S, Hallbôôk O, Wijma K. Vulvar vestibulitis is syndrome and vaginismus. J Reprod Med. 2000;45(3):219-223.

7. Reissing ED, Binik YM, Khalifé S, Cohen D, Amsel R. Vaginal spasm, pain and behaviour: an empirical investigation of the diagnosis of vaginismus. Arch Sex Behav. 2004;33(1):5-17.
8. Walker EA, Katon WJ, Neraas K, Jemelka RP, Massoth D. Dissociation in women with chronic pelvic pain. Am J Psychiatry. 1992;149(4):534-537.

9. Badura AS, Reiter RC, Altmaier EM, Rhomberg A, Elas D. Dissociation, somatization, substance abuse and coping in women with chronic pelvic pain. Obstet Gynecol. 1997;90(3):405-410.

10. Nijenhuis ER, van Dyck R, ter Kuile MM, Mourits MJ, Spinhoven P, van der Hart O. Evidence for associations among somatoform dissociation, psychological dissociation and reported trauma in patients with chronic pelvic pain. J Psychosom Obstet Gynecol. 2003;24(2):87-98.

11. American Psychiatric Association. DSM V-Diagnostic and Statistical Manual of Mental Disorders. 5th ed. St. Louis: American Psychiatric Association; 2013.

12. Malleson J. Vaginismus: its management and psychogenesis. Br Med J. 1942;2(4259):213-216.

13. Biswas A, Ratnam SS. Vaginismus and outcome of treatment. Ann Acad Med Singapore. 1995;24(5):755-758.

14. Dupree JK, Lehr ST, Hewell SW. Dyspareunia: three case reports. J Obstet Gynecol Neonatal Nurs. 1997;26(1):19-23.

15. Ward E, Ogden J. Experiencing vaginismus-sufferers' beliefs about causes and effects. Sex Mar Ther. 1994;9(1):33-45.

16. Silverstein JL. Origins of psychogenic vaginismus. Psychother Psychosom. 1989;52(4):197-204.

17. Özcan Ö, Cumurcu BE, Karlidağ R, Ünal S, Mutlu EA, Kartalci S. Attachment styles in women with vaginismus. Anat J Psychiatry. 2015; 16(1):37-43.

18. Abraham K. Manifestation of the female castration complex. Int $J$ Psycho-A. 1922;3:1-29.

19. Fenichel O. The psychoanalytic theory of neurosis. New York, NY: W.W. Norton and Company, Inc., 1945.

20. Oktay M, Tombul K. İki Yüz Vajinismus Vakasi ve Eşlerinin Psikolojik Yönden İncelenmesi [ 200 cases of vaginusmus, the patients and their husbands' psychological evaluation]. Yeni Symposium. 2003;41(212):115-119. Turkish.

21. Basson R. Lifelong vaginismus: a clinical study of 60 consecutive cases. J Soc Gynecol Obstet Can. 1996;18(6):551-561.

22. Nasab MM, Farnoosh Z. Management of vaginismus with cognitivebehavioral therapy, self-finger approach: a study of 70 cases. Iran J Med Sci. 2003;28(2):69-71.

23. Şar V. Kötüye kullanim ve ihmalle ilişkili sorunlar. In Güleç C, Köroğlu E, editors. Temel Psikiyatri. Ankara: Hekimler Yayin Birliği Yayincilik; 1997:823-834.

24. Nijenhuis ERS. Somatoform dissociation and somatoform dissociative disorders. In Dell P, O’Neil JO, editors. Dissociation and Dissociative Disorders. New York, NY: Routledge Press; 2009:261.

25. Nijenhuis ERS. Somatoform dissociation and somatoform dissociative disorders. In Dell P, O’Neil JO, editors. Dissociation and Dissociative Disorders. New York, NY: Routledge Press; 2009:259-275.

26. Şar V, Akyüz G, Kundakçi T, Kiziltan E, Doğan O. Childhood trauma, dissociation, and psychiatric comorbidity in patients with conversion disorder. Am J Psychiatry. 2004;161(12):2271-2276.

27. Saxe GN, Chinman G, Berkovitz R, et al. Somatization in patients with dissociative disorders. Am J Psychiatry. 1994;151(9):1329-1334.

28. Farina B, Mazzotti E, Pasquini P, Mantione MG. Somatoform and psychoform dissociation among women with orgasmic and sexual pain disorders. J Trauma Dissociation. 2011;12(5):526-534.

29. Spitzer RL, Williams JBW, Gibbon M, First MB. Structured Clinical Interview for DSM-III-R, Non-patient Edition (SCID-NP). Washington, DC: American Psychiatric Press; 1990.

30. First MB, Spitzer RL, Gibbon M, Williams JBW. Structured Clinical Interview for DSM-IV Axis I Disorders, Clinical Version (SCID-CV). Washington, DC: American Psychiatric Press; 1996.

31. Öztürkçügil A, Aydemir Ö, Yildiz M, Danacı AE, Köroğlu E. The reliability and validity of the Turkish version of the Structured Clinical İnterview for DSM-IV Axis 1 Disorders (SCID-I) IV. İlaç ve Tedavi Dergisi. 1999;12(4):233-236.

32. Sorias S, Saygili R, Elbi H. Turkish Version of the Structured Clinical Interview for DSM-III-R, non-patient edition. Bornova: Ege Üniversitesi Basımevi. 1990. Turkish. 
33. Bernstein DP, Fink L, Handelsman L, et al. Initial reliability and validity of a new retrospective measure of child abuse and neglect. Am J Psychiatry. 1994;151(8):1132-1136.

34. Bernstein DP, Stein JA, Newcomb MD, Walker E, Pogge D, Ahluvalia T, Stokes J, Handelsman L, Medrano M, Desmond D, Zule W. Development and validation of a brief screening version of the Childhood Trauma Questionnaire. Child Abuse Negl. 2003;27(2):169-90.

35. Şar V, Öztürk E, İkikardeş E. Validity and reliability of the Turkish version of the Childhood Trauma Questionnaire. J Med Sci. 2012; 32(4):1054-1063.

36. Bernstein EM, Putnam FW. Development, reliability and validity of a dissociation scale. J Nerv Ment Dis. 1986;174(12):727-735.

37. Yargiç LI, Tutkun H, Şar V. The reliability and validity of the Turkish Version of the Dissociative Experiences Scale. Dissociation. 1995; $8: 10-12$.

38. Şar V, Kundakçi T, Kiziltan E, Bakim B, Aydiner O. The reliability and validity of the Turkish version of the Somatoform Dissociation Questionnaire. Proceeding of the International Society of Dissociation 15th International Fall Conference. 1998, November 14-17, Seattle.

39. Atagün MI, Atagün Z, Doğan S, Evren C, Yalçinkaya EY, Öneş K. Sexual dysfunction is related with childhood trauma in female patients with fibromyalgia. Anatol J Psychiatry. 2013;14(3):200-209.

40. Yayla S, Bakim B, Tankaya O, Özer OA, Karamustafalioğlu O, Ertekin H, Tekin A. Psychiatric comorbidity in patients with conversion disorder and prevalence of dissociative symptoms. J Trauma Dissociation. 2015;16(1):29-38.

41. Taycan O, Şar V, Çelik C, Erdoğan-Taycan S. Trauma-related psychiatric comorbidity of somatization disorder among women in eastern Turkey. Compr Psychiatry. 2014;55(8):1837-1846.

42. Küçükgöncü S, Yildirim Örnek F, Cabalar M, Beştepe E, Yayla V. Childhood trauma and dissociation in tertiary care patients with migraine and tension type headache: a controlled study. JPsychosom Res. 2014;77(1):40-44.
43. Tristano AG. The impact of rheumatic disease on sexual function. Rheumatol Int. 2009;29(8):853-860.

44. Yunus MB, Arslan S, Aldag JC. Relationship between fibromyalgia features and smoking. Scand J Rheumatol. 2002;31(5):301-305.

45. Aydin G, Başar MM, Keleş I, Ergün G, Orkun S, Batislam E. Relationship between sexual dysfunction and psychiatric status in premenopausal women with fibromyalgia. Urology. 2006;67(1):156-161.

46. Ryan S, Hill J, Thwaites C, Dawes P. Assessing the effect of fibromyalgia on patients' sexual activity. Nurs Stand. 2008;23(2):35-41.

47. Shaver JL, Wilbur J, Robinson FP, Wang E, Buntin MS. Women's health issues with fibromyalgia syndrome. J Womens Health (Larchmt). 2006;15(9):1035-1045.

48. Carpenter MT, Hugler R, Enzenauer RJ, Des Rosier KF, Kirk JM, Brehm WT. Physical and sexual abuse in female patients with fibromyalgia. J Clin Rheumatol. 1998;4(6):301-306.

49. Walker EA, Keegan D, Gardner G, Sullivan M, Bernstein D, Katon WJ. Psychosocial factors in fibromyalgia compared with rheumatoid arthritis: II. Sexual, physical and emotional abuse and neglect. Psychosom Med. 1997;59(6):572-577.

50. Eden L, Ejlertsson G, Leden I, Nordbeck B. High rates of psychosomatic and neurotic symptoms among disability pensioners with musculoskeletal disorders. J Musculoskelet Pain. 2000;8(4):75-88.

51. Bellato E, Marini E, Castoldi F, et al. Fibromyalgia syndrome: etiology, pathogenesis, diagnosis and treatment. Pain Res Treat. 2012; 2012:426130.

52. Berkol TD, Balcioglu YH, Kirlioglu SS, Erensoy H, Vural M. Dissociative features of fibromyalgia syndrome. Neurosciences (Riyadh). 2017;22(3):198-204.

53. Walker E, Katon W, Harrop-Griffiths J, Holm L, Russo J, Hickok LR. Relationship of chronic pelvic pain to psychiatric diagnoses and childhood sexual abuse. Am J Psychiatry. 1988;145(1):75-80.
Neuropsychiatric Disease and Treatment

\section{Publish your work in this journal}

Neuropsychiatric Disease and Treatment is an international, peerreviewed journal of clinical therapeutics and pharmacology focusing on concise rapid reporting of clinical or pre-clinical studies on a range of neuropsychiatric and neurological disorders. This journal is indexed on PubMed Central, the 'PsycINFO' database and CAS,

\section{Dovepress}

and is the official journal of The International Neuropsychiatric Association (INA). The manuscript management system is completely online and includes a very quick and fair peer-review system, which is all easy to use. Visit http://www.dovepress.com/testimonials.php to read real quotes from published authors. 